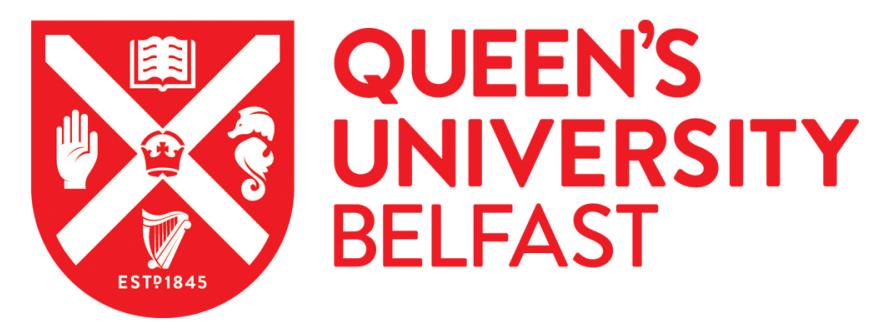

\title{
Hydrogel antimicrobial capture coatings for endotracheal tubes; a pharmaceutical strategy designed to prevent ventilator-associated pneumonia.
}

Jones, D. S., McCoy, C. P., Andrews, G. P., McCrory, R. M., \& Gorman, S. P. (2015). Hydrogel antimicrobial capture coatings for endotracheal tubes; a pharmaceutical strategy designed to prevent ventilator-associated pneumonia. Molecular Pharmaceutics, 12(8), 2928-2936. https://doi.org/10.1021/acs.molpharmaceut.5b00208

Published in:

Molecular Pharmaceutics

Document Version:

Peer reviewed version

Queen's University Belfast - Research Portal:

Link to publication record in Queen's University Belfast Research Portal

\section{Publisher rights}

This document is the Accepted Manuscript version of a Published Work that appeared in final form in Molecular Pharmaceutics, copyright 2015 @ American Chemical Society after peer review and technical editing by the publisher. To access the final edited and published work see http://pubs.acs.org/doi/abs/10.1021/acs.molpharmaceut.5b00208

\section{General rights}

Copyright for the publications made accessible via the Queen's University Belfast Research Portal is retained by the author(s) and / or other copyright owners and it is a condition of accessing these publications that users recognise and abide by the legal requirements associated with these rights.

Take down policy

The Research Portal is Queen's institutional repository that provides access to Queen's research output. Every effort has been made to ensure that content in the Research Portal does not infringe any person's rights, or applicable UK laws. If you discover content in the Research Portal that you believe breaches copyright or violates any law, please contact openaccess@qub.ac.uk. 
Hydrogel antimicrobial capture coatings for endotracheal tubes; a pharmaceutical strategy designed to prevent ventilator-associated pneumonia

David S. Jones, Colin P. McCoy, Gavin P. Andrews, Roisin M. McCrory and Sean P. Gorman

School of Pharmacy, The Queen's University of Belfast, Medical Biology Centre, 97 Lisburn Road, Belfast BT9 7BL, Northern Ireland, United Kingdom.

Author for correspondence: Professor David S. Jones, School of Pharmacy, The Queen's University of Belfast, Medical Biology Centre, 97, Lisburn Road, Belfast BT9 7BL, Northern Ireland, United Kingdom. Tel: +44 2890 272011, Fax: +44 2890247794 , e-mail: d.jones@qub.ac.uk 


\section{Abstract}

This paper presents a novel strategy for the prevention of ventilator-associated pneumonia that involves coating poly(vinylchloride, PVC) Endotracheal Tubes (ET) with hydrogels that may be subsequently used to entrap nebulised antimicrobial solutions. Candidate hydrogels were prepared containing a range of ratios of hydroxyethylmethacrylate (HEMA) and methacrylic acid (MAA) from 100:0 to 70:30 using free radical polymerisation and, when required, simultaneous attachment to PVC was performed. The mechanical properties, glass transition temperatures, swelling kinetics, uptake of gentamicin from an aqueous medium and gentamicin release were characterised. Increasing the MAA content of the hydrogels significantly decreased the ultimate tensile strength, \% elongation at break, Young's modulus and increased the glass transition temperature, the swelling ratio and gentamicin uptake. Microbial (Staphylococcus aureus and Pseudomonas aeruginosa) adherence to control (drug-free) hydrogels was observed however; whilst adherence to gentamicin-containing p(HEMA) occurred, no adherence occurred to gentamicin-containing HEMA: MAA copolymers. Antimicrobial persistence of gentamicin-containing hydrogels was examined by determining the zone of inhibition against each microorganism on successive days. Hydrogel composition affected the observed antimicrobial persistence, with the hydrogel composed of 70: 30 HEMA: MAA exhibiting $>20$ days persistence against $S$. aureus and $P$. aeruginosa, respectively. To simulate clinical use, the hydrogels (coated onto PVC) were firstly exposed to a nebulised solution of gentamicin (4mL, 80mg for 20 minutes), and then to nebulised bacteria ( $4 \mathrm{~mL}$ circa $1 \times 10^{9}$ colony forming units $\mathrm{mL}^{-1}$, 30 mins). Viable bacteria were not observed on the gentamicin-treated p(HEMA: MAA) copolymers whereas growth was observed on gentamicin-treated $\mathrm{p}(\mathrm{HEMA})$. In light of the excellent antimicrobial activity and physicochemical properties, p(HEMA: MAA) 
copolymers composed of ratios of $80: 20$ or 70: 30 HEMA: MAA were identified as potentially useful coatings of endotracheal tubes to be used in conjunction with the clinical nebulisation of gentamicin and designed for the prevention of ventilatorassociated pneumonia. 


\section{Introduction}

It has been widely reported that mechanical ventilation increases the risk of nosocomial pneumonia by a factor of 6 to $21^{1-5}$. Endotracheal intubation can facilitate the movement of organisms from the oropharynx into the trachea. Leakage around the cuff of the Endotracheal (ET) Tube allows pooled secretions above the cuff to enter the trachea and bronchi ${ }^{6}$. Bacteria amass on the surface of the ET tube, become irreversibly attached, producing extracellular polysaccharides and form a biofilm, where the sessile organisms are protected from host defences ${ }^{7-9}$. Assisted by ventilator flow or by suctioning, biofilm encased bacteria may become dislodged and travel into the lower airways ${ }^{10}$, resulting in ventilator associated pneumonia and the attendant associated considerable morbidity, mortality and increased hospital care costs ${ }^{11}$.

To optimise the performance of the ET tube, methods that can reduce or eliminate bacterial colonisation and/or augment the efficacy of antibiotics delivered locally or systemically should be pursued ${ }^{5,}{ }^{12}$. Technologies under consideration include subglottic secretion pooling (both above ${ }^{13}$ and below the cuff ${ }^{14}$ ), cuff design and operation and the use of antimicrobial-coated ET tubes ${ }^{5}$. The role of antimicrobial coatings to affect the resistance of the ET tube to biofilm formation (and hence ventilator associated pneumonia) has been examined in a number of studies. For example, Berra et al.. compared the clinical ability of silver sulfadiazine coated and noncoated (control) ET tubes to prevent bacterial colonisation and concluded that the antibiotic-coating prevented bacterial colonisation of the endotracheal tube for up to $24 \mathrm{~h}$ intubation ${ }^{15}$. Similarly, the ability of a silver-coated ET tube to delay the rate and extent of bacterial colonisation and bacterial bioburden has been reported ${ }^{16}$ whereas the ability of a silver sulphadiazine/chlorhexidine coating to eliminate/reduce bacterial 
colonisation in a sheep model has been described ${ }^{17}$. Contrary to these reports, in a clinical study, Kaflon et al. ${ }^{18}$ reported that silver-impregnated multi-lumen catheters were not associated with a lower colonisation rate than their non-silver impregnated counterparts when evaluated in a clinical scenario whereas Desai et al.. concluded that impregnation of catheters with silver or nitrofurazone did not significantly affect bacterial adherence in comparison to control catheters ${ }^{19}$. Whilst the evidence generally confirms the affirmative role of local antimicrobial delivery, it is appreciated that the delivery of the antimicrobial agent from such coatings is not fully understood nor optimised, particularly within the respiratory environment in which the volume of fluid for drug elution is limited.

In an innovative strategy, the authors (Adair et al..) described the use of nebulised gentamicin for the prevention of bacterial biofilm on ET tubes and hence ventilator associated pneumonia ${ }^{10}$. In a clinical study the authors reported that high concentrations of gentamicin were attained within the lumen of the ET tube following nebulisation resulting in an improved strategy for the prevention of ET tube biofilm when compared with parenterally administered cefoxatime. Accordingly, this study proved that if sufficient concentrations of antimicrobial agent are obtained within the lumen of the ET tube ventilator-associated pneumonia might be prevented. One of the limitations of this approach is the need for frequent nebulisation due to the negligible retention of the nebulised antibiotic at the luminal surface of the ET tube. Whilst it has been reported that there is minimal systemic absorption of gentamicin and good tolerance within the airways when administered by nebulisation ${ }^{20,21}$, it is clinically preferable to minimise the exposure of patients to antimicrobial agents to abate the development of multidrug resistant pathogens ${ }^{22-24}$. 
To address these concerns this study describes a pharmaceutical strategy in which candidate hydrogels are used as luminal coatings of ET tubes to specifically entrap nebulised antimicrobial solutions (gentamicin in this study). These coatings will therefore act as a platform for the subsequent delivery of gentamicin to bacteria adherent on the surface of the ET tube and hence reduce the frequency of nebulisation. This approach obviates the need to preload the ET tube with antimicrobial agent and allows the clinician to accurately control the usage of antimicrobial agent, thereby minimising the emergence of microbial resistance. This is the first report of the use of capture coatings for nebulised antimicrobial solutions and offers an exciting pharmaceutical strategy to reduce/prevent nosocomial pneumonia in the intensive care unit. 


\section{Materials and Methods}

\section{$2.1 \quad$ Materials}

2,2'-Azo-bis(2-methylpropionitrile) (AIBN) was purchased from BDH Laboratory Supplies (Poole, England). Mueller Hinton Agar (MHA) and Mueller Hinton Broth (MHB) were obtained from Oxoid Ltd (Basingstoke, England). Gentamicin sulfate USP and Tris base [tris(hydroxymethyl)aminomethane] were supplied by Taresh Chemicals (Banbridge, UK) and Melford Laboratories Ltd (Suffolk, England), respectively. 2-Hydroxyethyl methacrylate (HEMA) and methacrylic acid (MAA) were purchased from Lancaster (Eastgate, England). Medical grade PVC emulsion was obtained from Rusch Manufacturing Ltd. (Lurgan, Northern Ireland). PVC films were obtained from Goodfellow Cambridge Ltd. (Cambridgeshire, UK). All other chemicals were obtained from Sigma-Aldrich Co Ltd (Dorset England).

\subsection{Bacterial isolates}

The clinical isolates used in this study, namely Staphylococcus aureus and Pseudomonas aeruginosa, originated from microbial biofilm present on the surface of retrieved PVC endotracheal tubes from the intensive care unit of The Royal Victoria Hospital, Belfast. The organisms were maintained on beads (Protect Bacterial Preserve System, Technical Services Consultants Ltd., UK) and on agar in 10\% glycerol at $70^{\circ} \mathrm{C}$. Subculturing was performed at three monthly intervals, on MHA slopes stored at $4^{\circ} \mathrm{C}$. 


\subsection{Preparation of hydrogels and hydrogel-coated poly(vinyl chloride)}

A series of hydrogels were prepared by free radical polymerisation of 2hydroxyethylmethacrylate and methacrylic acid $(10,20,30 \% \mathrm{w} / \mathrm{w})$ using $1.0 \% \mathrm{w} / \mathrm{w}$ 2,2'-Azo-bis(2-methylpropionitrile) (AIBN) as an initiator, and cross-linked using $0.5 \%$

w/w ethylene glycol dimethacrylate, as previously described by the authors ${ }^{25,26}$. The monomer systems (including cross-linker and initiator) were injected into a mould compromising two glass sheets $(150 \times 100 \mathrm{~mm})$, which contained a loop of silicone tubing between a sheet of silicone coated release liner, and clamped together with bulldog clips to avoid leakage. The mould was then placed in a vacuum oven at $60^{\circ} \mathrm{C}$ for 18 hours, following which, the polymer was removed and washed in deionised water for 14 days to remove any unreacted monomers. All hydrogels were then stored in deionised water until required for analysis.

Poly(vinyl chloride, PVC) was prepared using emulsion polymerisation, as previously reported by the authors ${ }^{27}$. When required, coating of the hydrogels onto PVC was performed using a modification to the method described by McGinty and Brittain ${ }^{28}$. In this a section of PVC film $(3 \mathrm{~cm} \times 3 \mathrm{~cm} \times 200 \mu \mathrm{m})$ was immersed in a solution of monomer (HEMA, or various ratios of HEMA:MAA) containing 2,2'-azobisisobutyronitrile and ethylene glycol dimethacrylate, as described above. The mixture was covered and heated to $60^{\circ} \mathrm{C}$ in a thermostatically controlled oven until the acrylate layer became viscous. The sample was then removed and pressed between two glass plates before being returned to the oven at $60^{\circ} \mathrm{C}$ for 18 hours. Samples were removed and soaked in deionised water for 24 hours to remove remaining unpolymerized monomer. 


\subsection{Analysis of gentamicin using high performance liquid chromatography}

Due to the lack of a suitable chromophore, pre-column derivatisation of gentamicin was performed by reaction with excess 2,4-dinitrofluorobenzene. In this gentamicin was reacted with excess fluoro-2,4-dinitrobenzene-40 $\mu \mathrm{l}$ (50 mg in $1 \mathrm{~mL}$ acetonitrile), $100 \mu \mathrm{L}$ Tris buffer (165 mM, pH 12.0), $200 \mu \mathrm{l}$ acetonitrile, and $24 \mu \mathrm{L}$ of analyte solution, heated at $85^{\circ} \mathrm{C}$ in a shaking water bath for 1 hour in a sealed Eppendorf tube. Following this cooling was performed in an ice bath and the solutions were transferred to HPLC stoppered vials. HPLC analyses were performed on Shimadzu (Kyoto, Japan) HPLC instrumentation consisting of a model SIL-10AD VP auto injector, a model SCL-10A VP system controller, a model SPD-10A VP UV-VIS detector and LC-10AT VP liquid chromatograph (Dyson Instruments Ltd, Tyne \& Wear, UK). The Symmetry® C18 reverse phase column $(100 \mathrm{~mm} \times 4.6 \mathrm{~mm}, 3.5 \mu \mathrm{m})$ was obtained from Waters (MA, USA). HPLC analysis of the analyte solution ( $150 \mu \mathrm{L})$ containing derivatised gentamicin was performed at ambient temperature in isocratic mode, with the mobile phase, acetonitrile: Tris Buffer $8.25 \mathrm{mM}, \mathrm{pH} 7.0(75: 25 \mathrm{v} / \mathrm{v})$, delivered at $1.0 \mathrm{~mL} \mathrm{~min}^{-1}$. Components were detected at $365 \mathrm{~nm}$ and external standardisation was used. The mobile phase was filtered and degassed on a $0.45 \mu \mathrm{m}$ membrane (Millipore, Bedford, MA, USA) before use. The chromatographs obtained were analysed using Shimadzu Class VP® software. The relationship between peak area and concentration was linear (r> 0.99) over a concentration range of $5-250 \mu \mathrm{gL}^{-1}$.

\subsection{Preparation of gentamicin loaded hydroge/s}

Copolymers with a range of HEMA: MAA mass ratios (100:0, 90:10, 80:20, 70:30) were loaded with drug by immersion in a buffered gentamicin solution (isotonic Tris, pH 7.4, $50 \mathrm{mg} \mathrm{mL}^{-1}$ gentamicin sulfate) and placement in a shaking water bath (100 oscillations 
$\left.\min ^{-1}\right)$ at $37^{\circ} \mathrm{C}$. Prior to immersion each section of $\mathrm{p}(\mathrm{HEMA})$ and $\mathrm{p}(\mathrm{HEMA}-\mathrm{Co}-\mathrm{MAA})$ was dried in an oven. After immersion and prior to subsequent analysis of the materials, surface gentamicin solution was removed by placing the sample in a meshed metal basket and rinsing three times in isotonic Tris buffer, each for five seconds. The sample was then gently blotted dry between two pieces of filter paper. To quantify the mass of incorporated gentamicin, the drug was extracted five times into pre-heated buffered solution (isotonic Tris $\mathrm{pH} 7.4$ ) under shaking water conditions (100 oscillations $\mathrm{min}^{-1}$ ) at $37^{\circ} \mathrm{C}$. The mass of gentamicin in the various extracts was quantified using HPLC, as described above. To ensure all gentamicin was extracted, at the end of the analysis the samples were ground up in mortar and pestle, placed in fresh Tris buffer and the mass of drug quantified. All analyses were repeated at least five times.

\subsection{Buffer uptake of $p(H E M A)$ and $p(H E M A-c o-M A A)$ hydrogels}

Samples of hydrated $\mathrm{p}(\mathrm{HEMA})$ and $\mathrm{p}(\mathrm{HEMA}-\mathrm{Co}-\mathrm{MAA})$ were prepared and dried in an oven until a steady state weight was achieved. The discs were then accurately weighed,

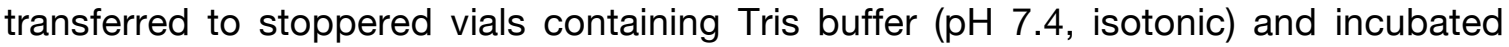
under shaking conditions at $37^{\circ} \mathrm{C}$. At pre-selected times each sample was removed, blotted dry between 2 pieces of filter paper and then reweighed before being returned to the stoppered vial containing Tris buffer $(\mathrm{pH} 7.4)$ until the next time period. The buffer uptake was defined as the swelling ratio (SR) using the following equation. At least five replicate analyses were performed.

$$
S R=\frac{W_{w}-W_{d}}{W_{d}}
$$

Where: 
$\mathrm{W}_{\mathrm{w}} \quad$ is the wet weight of the sample

$W_{d} \quad$ is the dry weight of the sample

\subsection{Determination of hydrogel network parameters}

From the swelling data the following network parameters were calculated ${ }^{29}$ :

(i) The molecular weight of the polymer chain between two neighbouring crosslinks $\left(\bar{M}_{c}\right)\left(\mathrm{g} \mathrm{mol}^{-1}\right)$

$\overline{\mathrm{M}}_{\mathrm{c}}=-\mathrm{d}_{\mathrm{p}} \mathrm{V}_{\mathrm{s}} \phi^{(-1 / 3)}\left[\ln (1-\phi)+\phi+\chi \phi^{2}\right]^{-1}$

Where:

$d_{p}$ is the density of the polymer $\left(\mathrm{g} \mathrm{cm}^{-1}\right)$

$V_{s}$ is the molar volume of the solvent $\left(18 \mathrm{~cm}^{3} \mathrm{~mol}^{-1}\right)$

$\mathrm{X}$ is the Flory-Huggins interaction parameter

$$
\text { (Calculated as } \left.\chi=0.5+\frac{\phi}{3}\right)^{30}
$$

$\phi$ is the volume fraction of the polymer in the swollen state, calculated using:

$\phi=\left[\left(\frac{d_{p}}{d_{s}}\right)\left(\frac{W_{\infty}-W_{o}}{W_{o}}\right)+1\right]^{-1}$, Where, in addition to the above:

$d_{s}$ is the density of the solvent $\left(\mathrm{g} \mathrm{cm}^{-3}\right)$

$W_{\infty}$ is the weight of the hydrogel at equilibrium

$\mathrm{W}_{\mathrm{o}}$ is the dry polymer weight

(ii) Cross-link density $\left(\mathrm{mol} \mathrm{cm}^{-3}, \rho\right)$

$\rho=\frac{\mathrm{d}_{\mathrm{p}}}{\overline{\mathrm{M}_{\mathrm{c}}}}$

(iii) Mean pore size $(\mathrm{nm})$ of the polymeric network of the hydrogel (द)

$\zeta=0.071 \phi^{(-1 / 3)} \sqrt{\overline{\mathrm{M}}_{\mathrm{c}}}$ 


\subsection{Tensile analysis}

The mechanical properties of the various equilibrium-hydrated hydrogels were determined using a Stable Micro Systems TA-XT2 Texture Analyser, as previously reported by the authors ${ }^{25}$. Tensile analysis was performed in accordance with the American Standards for Testing Materials guidance number D 638M. Dumbbell-shaped samples were fashioned from equilibrium-hydrated hydrogels and excess moisture was removed by gently patting the surface with filter paper. The samples were then immediately fixed between the clamps (mobile upper and static lower clamp) and held 5 $\mathrm{cm}$ apart with the aid of two adhesive pads (Sellotape ${ }^{\circledR}$ Sticky Fixers ${ }^{\mathrm{TM}}$ ). The upper clamp was raised at a constant crosshead speed of $1.0 \mathrm{~mm} \mathrm{~s}^{-1}$ until sample fracture occurred. In all cases at least 5 replicates of each analysis were performed. From the resultant relationship between the stress and strain, the ultimate tensile strength, Young's Modulus and \% elongation at break were calculated.

\subsection{Modulated temperature differential scanning calorimetry (MTDSC)}

The glass transition temperatures of dried $\mathrm{p}(\mathrm{HEMA})$ and $\mathrm{p}(\mathrm{HEMA}-\mathrm{Co}-\mathrm{MAA})$ hydrogels were analysed using a DSC 2920 Modulated DSC (TA Instruments, Leatherhead, UK) in modulated temperature mode with an attached refrigerated cooling system (RCS) unit. Calibration of the instrument was conducted using the melting of indium, cyclohexane and tin standards. Nitrogen was used as the purge gas, flowing at a rate of $30 \mathrm{~mL} \mathrm{~min}{ }^{-1}$ through the DSC cell and at $150 \mathrm{~mL} \mathrm{~min}^{-1}$ through the RCS unit. The mass of each empty sample pan matched the mass of the empty reference pan to $\pm 0.1 \mathrm{mg}$. TA Instruments aluminium pinhole hermetic pans were used throughout the experiments. Each analysis consisted of an initial two minute isothermal period at $25^{\circ} \mathrm{C}$ followed by a modulation amplitude of $\pm 0.21^{\circ} \mathrm{C}$ every 40 seconds with a $2^{\circ} \mathrm{C} \mathrm{min}{ }^{-1}$ underlying heating 
rate to $200^{\circ} \mathrm{C}$. Experiments were repeated at least 5 times for each candidate hydrogel. Modelling of the data was performed using the Gordon-Taylor equation ${ }^{31}$.

\subsection{Gentamicin release}

The release of gentamicin from the hydrogels as a function of time (under sink conditions) was performed by immersion of polymer samples in McCartney bottles that contained pre-heated buffer $(30 \mathrm{~mL}$, isotonic Tris, $\mathrm{pH} 7.4)$ which were then placed in a water bath under shaking conditions (100 oscillations $\mathrm{min}^{-1}$ ) at $37^{\circ} \mathrm{C}$. Prior to placement in the pre-heated isotonic buffer solution, excess surface solution was removed from the sample. At selected time intervals hydrogel samples were removed and immersed in fresh, pre-heated buffer (isotonic Tris, pH 7.4) to ensure sink conditions ${ }^{32,33}$. The mass of gentamicin released was then quantified by HPLC as described above.

\subsection{Bacterial adherence to $p(H E M A)$ and $p(H E M A-c o-M A A)$ hydrogels both} containing and devoid of with gentamicin

Adherence of stationary phase bacteria to $p(H E M A)$ and $p(H E M A-c o-M A A)$ hydrogels (either devoid of or containing gentamicin as defined in section 2.5) was examined

using a modification of a method previously reported by the authors ${ }^{27,34}$. In this, a volume $\left(20 \mathrm{~mL}\right.$, circa $1 \times 10^{8}$ colony forming units $\left.\mathrm{mL}^{-1}\right)$ of the bacterial suspension was added to McCartney bottles, each of which contained three hydrogel discs placed on a needle. The bottles were incubated in an orbital incubator $\left(37^{\circ} \mathrm{C}, 100\right.$ oscillations $\left.\mathrm{min}^{-1}\right)$ for periods of 1, 4 and 24 hours. Upon removal at the pre-selected times, the needles with attached samples were washed gently three times with $20 \mathrm{~mL}$ sterile peptone 
water to remove any non-adherent bacteria. Adherent bacteria were removed by placing the individual hydrogel discs in $10 \mathrm{~mL}$ volumes of peptone water, sonicating in an ultrasonic bath for 5 minutes and vortexing for 30 seconds. The number of adherent bacteria to each biomaterial was then determined by serial dilution.

\subsection{Bacterial viability on $p(H E M A)$ and $p(H E M A-c o-M A A)$ hydrogels following exposure to nebulised gentamicin}

In this method, samples of PVC with an attached hydrogel coating were prepared (surface area $25 \mathrm{~cm}^{2}$ ), fixed in position using a clamp and exposed to gentamicin via nebulisation ( $4 \mathrm{~mL}, 80 \mathrm{mg}$ for 20 minutes) or to isotonic Tris buffer (pH 7.4, as a control). The distance between the nebuliser and the material was maintained at $5 \mathrm{~cm}$. The dose and duration of nebulisation was selected on the basis of a previous report ${ }^{10}$. A suspension of bacteria ( $4 \mathrm{~mL}$ circa $1 \times 10^{9}$ colony forming units $\mathrm{mL}^{-1}$ ) was then aseptically transferred into the Hudson Micro Mist@ small volume nebulising chamber which was attached to the small volume nebuliser (DeVilbiss SunMist Plus $®$ ). The nebuliser was aimed at the hydrogel coatings and was permitted to run for a period of thirty minutes after which time samples of each material were removed from the material and viable bacterial adherence calculated as described above.

\subsection{Examination of antimicrobial persistence}

A volume $(0.5 \mathrm{~mL})$ of stationary phase S. aureus or Ps. aeruginosa (circa $2 \times 10^{7}$ colony forming units $\mathrm{mL}^{-1}$ ) was added to a sterile Petri dish and molten agar (20mL Mueller Hinton Agar) added. The dish was swirled to adequately mix the agar and then allowed to solidify. A gentamicin containing hydrogel sample (prepared as described in the materials and methods) was placed onto the agar surface using sterile forceps and the 
dish incubated at $37^{\circ} \mathrm{C}$ for 18 hours. After this period the zones of complete inhibition were measured ( $n \geq 5$ in each case). To investigate the persistence of activity of these materials the sample discs were removed from the agar plates after the first 18 hours of incubation and transferred, using sterile forceps, to a freshly seeded plate (S. aureus and Ps. aeruginosa respectively) and incubated for a further 18 hours. The persistence of activity was determined by transferring the samples to fresh seeded plates after each incubation period until no further zones were produced.

\subsection{Statistical analysis}

All experiments were performed at least five times and the results expressed as the mean \pm standard deviation. The effect of hydrogel composition on the mechanical properties, swelling properties, network parameters, drug loading and bacterial adherence (at each sampling point) were statistically evaluated using a one-way Analysis of Variance (ANOVA). The effects of hydrogel composition on gentamicin release and on the persistence of antimicrobial activity in the zone of inhibition assay were statistically evaluated using a repeated measures one-way ANOVA. Individual differences between the various materials in the above analyses were statistically identified using Tukey's HSD test. Linear regression analysis was performed when required and the significance of this assessed using the one-way ANOVA in association with examination of residuals. In all cases a probability of $p<0.05$ was selected to denote significance. 


\section{Results and Discussion}

The use of aerosolised antibiotics has been reported to be a successful strategy to prevent/reduce the incidence of ventilator-associated pneumonia. For example, Adair et al. ${ }^{10}$ compared the efficacy of nebulised gentamicin with that of conventional antibiotic prophylaxis to prevent the formation of microbial biofilm on the ET tubes of ICU patients. In this no pathogens were recovered from the ET tubes which received nebulised gentamicin, whereas Wood et al. reported a reduction of $73 \%$ in the incidence of VAP in those patients assigned nebulised ceftazidime compared to patients who received placebo after two weeks ${ }^{35}$. One limitation of these approaches, which this current study addresses, is the poor retention of the nebulised antimicrobial agent at the inner surface of the endotracheal tube. The location of the nebulised antimicrobial agent within a coating on the luminal surface of the tube will serve to concentrate and localise the antimicrobial agent, thereby offering an enhanced antimicrobial effect against adherent microorganisms, a lower required frequency of nebulisation and minimisation of the possible emergence of resistant bacterial strains.

\subsection{Attachment of Hydrogels to PVC}

To perform as an effective coating, it is essential to ensure that the coating remains attached to the polymeric substrate. In this study successful, irreversible coating of PVC was performed using a modification of the method of McGinty and Brittain ${ }^{28}$ and resulted in hydrogel layers of approximately $200 \mu \mathrm{m}$ thickness on a PVC substrate. Attachment of the coating to the substrate was robust and homogeneous following equilibrium swelling. 


\subsection{Physicochemical Properties of Hydrogels}

The hydrogel systems described in this study are designed as coatings for PVC ET tubes and therefore the bulk mechanical properties of the coated ET tubes would be principally derived from the PVC component. However, it is important that the mechanical properties of the coatings are sufficiently robust to withstand the normal deformations encountered during insertion and removal of the device. Mechanical failure of the coating may result in shedding into the lungs, which will have implications for respiratory function.

The effect of material composition on the mechanical properties of the hydrogels and the glass transition temperatures of the xerogels are shown in table 1. As may be observed, the glass transition temperatures of the dehydrated materials were dependent on the MAA content. The glass transition temperature of $p(H E M A)$ was $114.94 \pm 1.58^{\circ} \mathrm{C}$ and this was sequentially (and linearly) raised by increasing the composition of MAA, with the glass transition temperature of $\mathrm{p}(\mathrm{HEMA}-\mathrm{Co}-\mathrm{MAA}, 70: 30)$ being $146.76 \pm 3.57^{\circ} \mathrm{C}$. Modelling of the glass transition data was performed using the Gordon-Taylor equation $^{31}$, from which it was confirmed that a positive correlation between glass transition temperature and weight fraction of $\mathrm{p}(\mathrm{HEMA})$ existed. Based on this information it may be concluded that the hydrogels were copolymers and not polymer blends ${ }^{36}$

The mechanical properties of the equilibrium-swollen hydrogels under examination were dependent on the mass of MAA but not on the presence of gentamicin. Increasing the MAA composition of the materials significantly decreased the \% elongation at break, the ultimate tensile strength and the Young's modulus. The 
inability of gentamicin to adversely affect the mechanical properties illustrates that, whilst this drug may interact with the carboxylic acid group of the MAA-containing hydrogels ${ }^{37,38}$, this interaction is insufficient to compromise the mechanical properties of the swollen hydrogels. The mechanical properties of the hydrogel coatings were directly dependent on the ratio of HEMA:MAA. Decreasing the HEMA:MAA ratio significantly and sequentially decreased the ultimate tensile strength, elongation at break and Young's modulus. These observations may be accredited to the effects on MAA on the molecular weight of the polymer chain between two neighbouring cross links. The effects of MAA on the mechanical properties of HEMA are in accordance with previous reports ${ }^{39,}{ }^{40}$. Despite the reductions in the mechanical properties associated with the incorporation of MAA within the copolymers, the magnitude of these properties would be sufficient as coatings on PVC. The hydrogels were able to withstand considerable deformation and shear stresses, such as those experienced upon insertion/removal of the ET tubes, prior to fracture.

\subsection{Hydrogel Swelling Studies and Network Parameters}

The buffer uptake properties of $\mathrm{p}(\mathrm{HEMA})$ and $\mathrm{p}(\mathrm{HEMA}-\mathrm{co}-\mathrm{MAA})$ are displayed in Figure 1. As may be observed the relationship between swelling ratio and time was non-linear for each material. The greatest swelling ratio (at equilibrium uptake) was exhibited by the copolymer composed of $\mathrm{p}($ HEMA-co-MAA, 70:30) $(3.56 \pm 0.34)$ whereas the lowest swelling ratio was associated with $\mathrm{p}(\mathrm{HEMA})$ homopolymer $(0.57 \pm 0.01)$. The other materials exhibited swelling ratios that were significantly different from one another and lay between these values. Modelling of the swelling properties was performed using a power law model to provide information on the mechanism of swelling, defined using the exponent $(n)(\text { Table 2) })^{37,}{ }^{41}$. From this it was observed that the exponent 
significantly increased as the mass of MAA was increased within the biomaterials. Hence the greatest exponent was displayed by $\mathrm{p}(\mathrm{HEMA}-\mathrm{co}-\mathrm{MAA}, 70: 30)$ whereas the lowest value of this parameter was associated with $\mathrm{p}(\mathrm{HEMA})$. The ability of copolymers of HEMA:MAA to exhibit greater swelling than $\mathrm{p}(\mathrm{HEMA})$ is accredited to the ability of the hydrogels to ionise and undergo charge-mediated, polymer chain repulsion ${ }^{42}$. Consideration of the swelling exponents confirmed that the mechanism of buffer uptake by $\mathrm{p}(\mathrm{HEMA})$ and the various copolymers was anomalous and is in accordance with a combination of factors, including the rate of ionisation at the glassy/rubbery interface ${ }^{37}$. The uptake of gentamicin was directly related to the swelling properties; with materials exhibiting increased swelling showing the greatest mass of absorbed gentamicin (Table 2). Accordingly, decreasing the ratio of HEMA to MAA in the hydrogels significantly increased the loading of gentamicin, reaching a maximum at a hydrogel ratio of 70:30.

The network parameters associated with the various hydrogels, calculated using swelling data ${ }^{29}$, are presented in Table 2. As the ratio of HEMA:MAA within the hydrogels was decreased sequentially from 100:0 to 70:30 the molecular weight of the polymer chain between two neighbouring cross links and the mesh size increased whereas the cross link density and the volume fraction of the polymer in the swollen state decreased. Accordingly, as the mass of MAA within the hydrogels increased (and at physiological $\mathrm{pH}$ under which conditions there is $>99 \%$ ionisation of the carboxylic acid groups), the increased mesh size facilitated fluid absorption. The uptake of gentamicin into the fluid filled regions between the polymer chains was dependent on the mesh size. Assuming the hydrodynamic radius of gentamicin is similar to that of other small organic drug molecules ${ }^{43}$, the lower mesh size of $p(H E M A)(1.81 \pm 0.00 n m)$ will act to preclude drug uptake within the mesh volume. As the mesh size increases 
the uptake of gentamicin increases thereby facilitating gentamicin uptake. The uptake of gentamicin into the hydrogel composed of 70:30 HEMA:MAA (mesh size $39.18 \pm 1.83 \mathrm{~nm})$ was greater than into the hydrogel composed of $80: 20$ HEMA:MAA hydrogel (mesh size $33.64 \pm 1.59 \mathrm{~nm}$ ) however the extent of the uptake of gentamicin into the 90:10 HEMA:MAA hydrogel (mesh size $24.43 \pm 1.02 \mathrm{~nm}$ ) was markedly less. Accordingly a mesh size of $>30 \mathrm{~nm}$ facilitates substantial loading of this hydrogel with gentamicin.

\subsection{Gentamicin Release from Hydrogels}

The composition of the hydrogels significantly affected the subsequent mass of gentamicin released as a function of time (Figure 2a). The release of gentamicin from $\mathrm{p}(\mathrm{HEMA})$ was rapid and uncontrolled (with low released mass) due to the low drug loading (and surface location) of gentamicin (data not shown). Consequently $100 \%$ drug release had occurred by the first sampling period (15mins). The overall mass of drug released was dependent on the initial drug loading (table 2), which was, in turn, significantly affected by the composition of the hydrogel. Figure $2 \mathrm{~b}$ represents the data as the fractional drug release to facilitate comparison of the release rates of the gentamicin from the three hydrogels. As may be observed, the release of gentamicin was relatively rapid from the hydrogel co-polymers, with $50 \%$ release occurring within the first 15 minutes. The release rates of gentamicin from the hydrogels composed of 90:10 and 80:20 HEMA:MAA were statistically similar. These observations are in line with other publications in which a rapid release of therapeutic agents from p(HEMA)-based hydrogels has been reported, e.g. Alfuzosin Hydrochloride ${ }^{44}$, Timolol Maleate ${ }^{45}$ and Ciprofloxacin Hydrochloride ${ }^{46}$. 
Based on these observations, the $\mathrm{p}(\mathrm{HEMA})$ hydrogel did not offer suitable properties (drug uptake and release) to be considered as a suitable as a gentamicin capture coating designed for the prevention of ventilator-associated pneumonia. However, the properties of the other co-polymers showed promise in this regard.

\subsection{Antimicrobial and Microbial Anti-Adherence Properties of Hydrogels}

The National Nosocomial Infection Surveillance (NNIS) system reported that mechanical ventilation was implicated in $83 \%$ of episodes of nosocomial pneumonia, with endotracheal intubation cited as an obvious predisposing factor for ventilatorassociated pneumonia ${ }^{47}$. S. aureus and Ps. aeruginosa have emerged as the principal causative organisms of ventilator-associated pneumonia ${ }^{48,49}$. Therefore clinical isolates of these pathogens were selected to evaluate the antimicrobial properties of the candidate hydrogels. These properties of the hydrogels were assessed in terms of their resistance to microbial adherence and the persistence of antimicrobial activity, the latter assessed using a seed plate method. Microbial adherence to biomaterials is accepted to represent the initial stage of medical device colonisation ${ }^{38,50,51}$ and thereby reduction/inhibition of this process represents a critical stage in the development of infection resistance medical biomaterials. The effects of gentamicin treatment and time on the adherence of $S$. aureus and Ps. aeruginosa to $\mathrm{p}(\mathrm{HEMA})$ and $\mathrm{p}(\mathrm{HEMA}-\mathrm{Co}-\mathrm{MAA})$ hydrogels are displayed in Tables 3 and 4, respectively. The composition of the hydrogels and the contact time significantly affected microbial adherence. However, whilst individual differences in the time and hydrogel composition were observed, no overall trends were observed. More importantly, gentamicin-containing hydrogel copolymers inhibited the adherence of both microorganisms at each time period studied. Conversely, adherence of both microorganisms to gentamicin-loaded 
$\mathrm{p}(\mathrm{HEMA})$ was observed however, this was significantly lower ( $>90 \%$ reduction) than to $\mathrm{p}(\mathrm{HEMA})$ devoid of gentamicin. The inability of gentamicin-containing $\mathrm{p}(\mathrm{HEMA})$ hydrogel to inhibit adherence is directly related to the low drug loading and negligible drug release from this biomaterial.

The persistence of antimicrobial activity, expressed as zones of inhibition of the various gentamicin-containing hydrogels against $P$ s. aeruginosa and $S$. aureus, are shown in Figures 3 and 4 , respectively. It should be noted that the results illustrate the persistence of the hydrogels obtained by following the antimicrobial activity over sequential transfers. This method is useful for two reasons. Firstly, the antimicrobial activity of the hydrogels may be examined following a series of successive microbial challenges. Secondly, as the antimicrobial activity in this method results from diffusion of drug from the hydrogel, this method provides an indication of drug release under non-sink conditions. Given that when used in vivo the fluid content on the luminal side of the ET tube (to which the hydrogel is attached) will be minimal (and only results from the nebulisation process and the inspiration of humid air), the conditions under which drug release will occur will be non-sink. Therefore, this method is of particular relevance given the non-sink conditions that operate in vivo. As may be observed, all hydrogel polymers exhibited antimicrobial persistence, denoted by the significant zones of inhibition on successive days, against $S$. aureus and Ps. aeruginosa. Maximum antimicrobial persistence against both bacteria was associated with the hydrogel copolymer composed of 70:30 HEMA: MAA, with persistence lasting $>30$ days and $>20$ days for $S$. aureus and Ps. aeruginosa, respectively. Significant differences in antimicrobial persistence between each 
hydrogel were observed however, for both microorganisms, $\mathrm{p}(\mathrm{HEMA})$ had minimal antimicrobial persistence, due to the low drug loading and rapid release of gentamicin from this biomaterial.

To simulate the performance of these hydrogel systems under clinical conditions, this study examined the ability of the coatings that had been pre-treated by nebulisation with a solution of gentamicin (using a clinical nebuliser) or Tris buffer (as a control) and then exposed to nebulised bacteria, to resist microbial colonisation on the surface of the coating. Microbial survival on exemplar hydrogels either containing or devoid of (nebulised) gentamicin is shown in Table 5. Following nebulisation of both microorganisms on each control (non-gentamicin treated) material microbial colonisation resulted, the extent of which was dependent on the composition of the hydrogel. Importantly, microbial colonisation on the p(HEMA: MAA) copolymers that had previously been exposed to gentamicin via nebulisation was not observed. Conversely, microbial adherence was observed on $\mathrm{p}(\mathrm{HEMA})$ that had previously been exposed to gentamicin however, the extent of this was dramatically lower than to control (non-treated) $\mathrm{p}(\mathrm{HEMA})$. In this experimental method, gentamicin was not released into a bathing solution and therefore the concentration and availability of gentamicin relates to the concentration of this antimicrobial agent within the aqueous filled pores of the polymer matrix. Upon contact with the hydrogel, the bacteria will be in direct contact with this gentamicin-containing aqueous interface and therefore gentamicin will be directly available to exert its antimicrobial effect. Furthermore, it should be noted that the available gentamicin concentration will far exceed that which may be obtained following administration of this drug by other means ${ }^{10}$. The activity of $\mathrm{p}(\mathrm{HEMA})$ was inferior to the hydrogel copolymers and may be accredited to the lower 
uptake of gentamicin within the matrix of this polymer following nebulisation and hence the lower availability of antimicrobial agent.

\section{Conclusions}

This study uniquely describes a novel pharmaceutical strategy for the prevention of ventilator-associated pneumonia, in which candidate hydrogel coatings ( $($ HEMA) and $\mathrm{p}(\mathrm{HEMA}-\mathrm{Co}-\mathrm{MAA})$ ) on PVC have been designed to entrap gentamicin following nebulisation of solutions of this antimicrobial agent. The physicochemical properties of the hydrogels, namely the uptake of gentamicin, swelling, gentamicin release, mechanical properties and calculated network parameters were dependent on the ratio of HEMA to MAA. Microbial (S. aureus and Ps. aeruginosa) adherence to control (nongentamicin containing) coatings was dependent on the coating composition. Following the inclusion of gentamicin, either by immersion in or by nebulisation of a solution of gentamicin, microbial growth on the hydrogel copolymers was not observed, however, growth was observed on $\mathrm{p}(\mathrm{HEMA})$. Similarly, antimicrobial persistence (determined using zone of inhibition measurements against both microorganisms on successive days) was observed for the hydrogel copolymers ( $>20$ days) whereas only limited persistence was associated with gentamicin-containing $\mathrm{p}(\mathrm{HEMA})$. These observed differences were directly related to the rate and extent of gentamicin uptake. In light of the excellent antimicrobial activity and physicochemical properties, p(HEMA: MAA) copolymers composed of ratios of $80: 20$ or 70: 30 HEMA: MAA are useful coatings of endotracheal tubes to be used in conjunction with the clinical nebulisation of gentamicin. It is proposed that the use of these coatings in conjunction with gentamicin nebulisation would be beneficial for the prevention of ventilator-associated pneumonia. 


\section{References}

1. Rello, J.; Diaz, E.; Roque, M.; Valles, J. Risk factors for developing pneumonia within 48 hours of intubation. Am. J. Respir. Crit. Care Med. 1999, 159, 1742-1746.

2. Craven, D.; Steger, K.; Barber, T. Preventing nosocomial pneumonia: state of the art and perspectives or the 1990s. Am. J. Med. 1991, 91, 44S-53S.

3. Baker, A.; Meredith, J.; Haponik, E. Pneumonia in intubated trauma patients: Microbiology and outcomes. Am. J. Respir. Crit. Care Med. 1996, 153, 343-349.

4. Cavalcanti, M.; Ferrer, M.; Ferrer, R.; Morforte, R.; Garnacho, A.; Torres, A. Risk and prognostic factors of ventilator-associated pneumonia in trauma patients. Crit. Care Med. 2006, 34, (4), 1067-1072.

5. Pinciroli, R.; Mietto, C.; Berra, L. Respiratory therapy device modifications to prevent ventilator-associated pneumonia. Curr. Opin. Infect. Dis. 2013, 26, (2), 175-183. 6. Rumbak, M. Ventilator-associated pnemonia. J. Respir. Dis. 2000, 21, 321-327. 7. Macassey, E.; Dawes, P. Biofilms and their role in otorhinolaryngological disease. J. Laryng. Otol. 2008, 122, (12), 1273-1278.

8. Sottile, F.; Marries, T.; Prough, D.; Hobgood, C.; Gower, D.; Webb, L.; Costerton, J.; Gristina, A. Nosocomial pulmonary infection: Possible etiologic significance of bacterial adhesion to endotracheal tubes. Crit. Care Med. 1986, 14, 265270.

9. Adair, C. G.; Gorman, S. P.; Feron, B. M.; Byers, L. M.; Jones, D. S.; Goldsmith, C. E.; Moore, J. E.; Kerr, J. R.; Curran, M. D.; Hogg, G.; Webb, C. H.; McCarthy, G. J.; Milligan, K. R. Implications of endotracheal tube biofilm for ventilator- associated pneumonia. Intensive Care Med. 1999, 25, (10), 1072-1076. 
10. Adair, C. G.; Gorman, S. P.; Byers, L. M.; Jones, D. S.; Feron, B.; Crowe, M.; Webb, H. C.; McCarthy, G. J.; Milligan, K. R. Eradication of endotracheal tube biofilm by nebulised gentamicin. Intens. Care Med. 2002, 28, (4), 426-431.

11. Rello, J.; Ollendorf, D. A.; Oster, G.; Vera-Llonch, M.; Bellm, L.; Redman, R.; Kollef, M. H. Epidemiology and outcomes of ventilator-associated pneumonia in a large US database. Chest 2002, 122, 2115-2121.

12. Bouadma, L.; Wolff, M.; Lucet, J. M. Ventilator-associated pneumonia and its prevention. Curr. Opin. Infect. Dis. 2012, 25, (4), 395-403.

13. Wang, F.; Bo, L.; Tang, L.; Lou, J.; Wu, Y.; Chen, F.; Li, J.; Deng, X. Subglottic secretion drainage for preventing ventilator-associated pneumonia: An updated metaanalysis of randomised controlled trials. J. Trauma Acute Care Surg. 2012, 72, (5), 1276-1285.

14. Li Bassi, G.; Curto, F.; Zanella, A.; Stylianou, M.; Kolobow, T. A 72-hour study to test the efficacy and safety of the "Mucus Slurper" in mechanically ventilated sheep. Crit. Care Med. 2007, 35, (3), 906-911.

15. Berra, L.; Kolobow, T.; Laquerriere, P.; Pitts, B.; Bramati, S.; Pohlmann, J.; Marelli, C.; Panzeri, M.; Brambillasca, P.; Villa, F.; Baccarelli, A.; Bouthors, S.; Stelfox, H.; Bigatello, L.; Moss, J.; Pesenti, A. Internally coated endotracheal tubes with silver sulfadiazine in polyurethane to prevent bacterial colonisation: a clinical trial. Inten. Care Med. 2008, 34, 1030-1037.

16. Rello, J.; Kollef, M.; Diaz, E.; Sandiumenge, A.; del Castillo, Y.; Corbella, X.; Zachskorn, R. Reduced burden of bacteral airway colonisation with a novel silvercoated endotracheal tube in a randomised multiple-center feasibility study. Crit. Care Med. 2006, 34, (11), 2766-2772. 
17. Berra, L.; De Marchi, L.; Yu, Z., X.,; Laquerriere, P.; Baccarelli, A.; Kolobow, T. Endotracheal tubes coated with antiseptics decrease bacterial colonisation of the ventilator circuits, lungs and endotracheal tube. Anaesthesiology 2004, 100, 1446-1156. 18. Kaflon, P.; De Vaumas, C.; Samba, D.; Boulet, E.; Lefrant, J.; Eyraud, D.; Lherm, T.; Santoli, F.; Naija, W.; Riou, B. Comparison of silver-impregnated with standard multi-lumen central venous catheters in critically ill patients. Crit. Care Med. 2007, 35, (4), 1032-1039.

19. Desai, D. G.; Liao, K. S.; Cevallos, M. E.; Trautner, B. W. Silver of Nitrofurazone Impregnation of Urinary Catheters has a Minimal Effect on Uropathogen Adherence. J. Urol. 2010, 184, (6), 2565-2571.

20. Sheridan, M.; Armstrong, C. Dosing regimens for nebulised gentamicin in intensive care. Br. J. Anaesth. 1998, 81, 648.

21. Palmer, L.; Smaldone, G.; Simon, S.; O'Riordan, T.; Cuccia, A. Aerosolised antibiotics in mechanically ventilated patients: delivery and response. Crit. Care Med. 1998, 26, 31-39.

22. Kollef, M. Antimicrobial therapy of ventilator-associated pneumonia. Chest $1999,115,8-11$.

23. Kollef, M. The prevention of ventilator-associated pneumonia. New Eng. J. Med. 1999, 340, 627-634.

24. Tambyah, P. A.; Oon, J. Catheter-Associated Urinary Tract Infection. Curr. Opin. Infect. Dis. 2012, 25, (4), 365-370.

25. Jones, D. S.; McLaughlin, D. W. J.; McCoy, C. P.; Gorman, S. P. Physicochemical characterisation and biological evaluation of hydrogel-poly(e- 
caprolactone) interpenetrating polymer networks as novel urinary biomaterials. Biomaterials 2005, 26, (14), 1761-1770.

26. Jones, D. S.; Andrews, G. P.; Gorman, S. P. Characterisation of cross-linking effects on the physicochemical and drug diffusional properties of cationic hydrogels designed as bioactive urological biomaterials. J. Pharm. Pharmacol. 2005, 57, 12511259.

27. Jones, D. S.; McGovern, J. G.; Woolfson, A. D.; Gorman, S. P. Role of physiological conditions in the oropharynx on the adherence of respiratory bacterial isolates to endotracheal tube poly(vinyl chloride). Biomaterials 1997, 18, (6), 503-510.

28. McGinty, K.; Brittain, W. Hydrophilic surface modification of poly(vinyl chloride) film and tubing using physisorbed free radical grafting technique. Polymer 2008, 49, $4350-4357$.

29. Singh, B.; Varshney, L.; Sharma, V. Design of sterile mucoadhesive hydrogels for use in drug delivery: Effect of radiation on network structure. Colloids and Surfaces B: Biointerfaces 2014, 121, 230-237.

30. Lowmann, A. M.; Peppas, N. A., In Encyclopaedia of Controlled Drug Delivery, Mathiowitz, E., Ed. New York, 1999; p 397.

31. Gordon, M.; Taylor, J. Ideal copolymers and the second-order transitions of synthetic rubbers. 1. Non-crystalline polymers. J. Appl. Chem. 1952, 2, 493-500.

32. Gibaldi, M.; Feldman, S. Establishment of sink conditions in dissolution rate determinations. Theoretical considerations and application to non-disintegrating dosage forms. . Journal of Pharmaceutcial Sciences 1967, 56, 1238-1242.

33. Dokoumetzidis, A.; Mancheras, P. A century of dissolution research: From Noyes and Whitney to the Biopharmaceutics Classification System. International Journal of Pharmaceutics 2006, 321, 1-11. 
34. Jones, D. S.; Djokic, J.; S.P., G. An examination of the resistance of polyvinylpyrrolidone-lodine-poly(e-caprolactone) blends to adherence of Escherichia coli. Biomaterials 2005, 26, (14), 2013-2020.

35. Wood, G.; Boucher, B.; Croce, M.; Hanes, S.; Herring, V.; Fabian, T. Aerosolised ceftazidime for prevention of ventilator-associated pneumonia and drug effects on the proinflammatory response in critically ill trauma patients. Pharmacotherapy 2002, 22, 972-982.

36. Iglesias, M.; Guzman, J.; Riande, E. Copolymerisation and terpolymerisation of methacrylic ester monomers containing hydroxyl groups in their structure. Polymer 1996, 37, 1443-1452.

37. Khare, A. R.; Peppas, N. A. Release behaviour of bioactive agents from pHsensitive hydrogels. Journal of Biomaterials Science Polymer Edition 1993, 4, 275 - 289. 38. Parsons, C.; McCcoy, C.; Gorman, S.; Jones, D.; Bell, S.; Brady, C.; McGlinchey, S. Anti-infective photodynamic biomaterials for the prevention of intraocular lens-associated infectious endophthalmitis. Biomaterials 2009, 30, (4), 597602.

39. Tranoudis, I.; Efron, N. Tensile properties of soft contact lens materials. Contact Lens and Anterior Eye 2004, 27, 177-191.

40. Peppas, N. A.; Yang, W. H. M. Properties-based optimisation of the structure of polymers for contact lens applications. Contact Intraocular Lens Medicince Journal $1981,7,300-314$

41. Peppas, N. A. Analysis of Fickian and Non-Fickian Drug Release from Polymers. Pharmaceut. Acta Helv. 1985, 60, (4), 110-111. 
42. Bell, L. C.; Peppas, A. N. Swelling/syneresis phenomena in gel-forming interpolymer complexes. J. Biomater. Sci. Polym. Ed. 1996, 7, 671-683.

43. Ye, F.; Jensen, H.; Larsen, S. W.; Yaghmur, A.; Larsen, C.; Ostergaard, J. Measurement of drug diffusivities in pharmaceutical solvents using Taylor dispersion analysis. J. Pharm. Biomed. Anal. 2012, 61, 176-183.

44. Mohapatra, R.; Ray, D.; Swain, A. K.; Pal, T. K.; Sahoo, P. K. Release Study of Alfuzosin Hydrochloride Loaded to Novel Hydrogel P(HEMA-co-AA). 0021-8995 2008, 108, (1).

45. Silva, A. S. G.; Pinheiro, M. N. C. Diffusion Coefficients of Timolol Maleate in Polymeric Membranes Based on Methacrylate Hydrogels. Journal of Chemical Engineering Data 2013, 58, 2280-2289.

46. Tsou, T. L.; Tang, S. T.; Huang, Y. C.; Wu, J. R.; Young, J. J.; Wang, H. J. Poly(2-hydroxyethyl methacrylate) wound dressing containing ciprofloxacin and its drug release studies. Journal of Materials Science: Materials in Medicine 2005, 16, 95-100.

47. Richards, M. J.; Edwards, J. R.; Culver, D. H.; Gaynes, R. P. Nosocomial infections in combined medical-surgical intensive care units in the United States. Infect. Cont. Hosp. Epidemiol. 2000, 21, (8), 510-515.

48. Fridkin, S.; Gaynes, R. Antimicrobial resistance in intensive care units. Clin. Chest Med. 1999, 20, 303-308.

49. McCrory, R.; Jones, D. S.; Adair, C. G.; Gorman, S. P. Pharmaceutical strategies to prevent ventilator-associated pneumonia. J. Pharm. Pharmacol. 2003, 55, (4), 411-428.

50. Broekhuizen, C. A. N.; de Boer, L.; Schipper, K.; Jones, C. D.; Quadir, S.; Feldman, R. G.; Vandenbroucke-Grauls, C.; Zaat, S. A. J. The influence of antibodies 
on Staphylococcus epidermidis adherence to polyvinylpyrrolidone-coated silicone elastomer in experimental biomaterial-associated infection in mice. Biomaterials 2009, 30, (32), 6444-6450.

51. Jones, D. S.; Gorman, S. P.; McCafferty, D. F.; Woolfson, A. D. The Effects of 3 Non-Antibiotic, Antimicrobial Agents on the Surface Hydrophobicity of Certain Microorganisms Evaluated by Different Methods. J. Appl. Bacteriol. 1991, 71, (3), 218227. 


\section{Legends}

Figure 1. The effect of hydrogel composition on the swelling ratio (Tris buffer, pH 7.4 containing $50 \mathrm{mg} \mathrm{mL}^{-1}$ gentamicin sulfate). Symbols: closed circles p(HEMA), closed diamonds 90:10 p(HEMA-co-MAA), closed triangles 80:20 p(HEMA-co-MAA), closed squares 70:30 p(HEMA-co-MAA), open triangles 60:40 p(HEMA-co-MAA).

Figure 2. The effect of hydrogel composition on gentamicin release (Tris buffer, $\mathrm{pH}$ 7.4). Figure $2 \mathrm{a}$ expresses drug release in terms of the cumulative mass of gentamicin released as a function of time whereas Figure $2 b$ expresses the fractional drug released as a function of time. Symbols: closed diamonds 90:10 p(HEMA-co-MAA), closed triangles 80:20 p(HEMA-co-MAA), closed squares 70:30 p(HEMA-co-MAA

Figure 3. The effect of hydrogel composition on the zone of inhibition of PS. aeruginosa. Symbols: closed circles p(HEMA), closed diamonds 90:10 p(HEMA-coMAA), closed triangles 80:20 p(HEMA-co-MAA), closed squares 70:30 p(HEMA-coMAA)

Figure 4. The effect of hydrogel composition on the zone of inhibition of S. aureus. Symbols: closed circles p(HEMA), closed diamonds 90:10 p(HEMA-co-MAA), closed triangles 80:20 p(HEMA-co-MAA), closed squares 70:30 p(HEMA-co-MAA) 
Figure 1

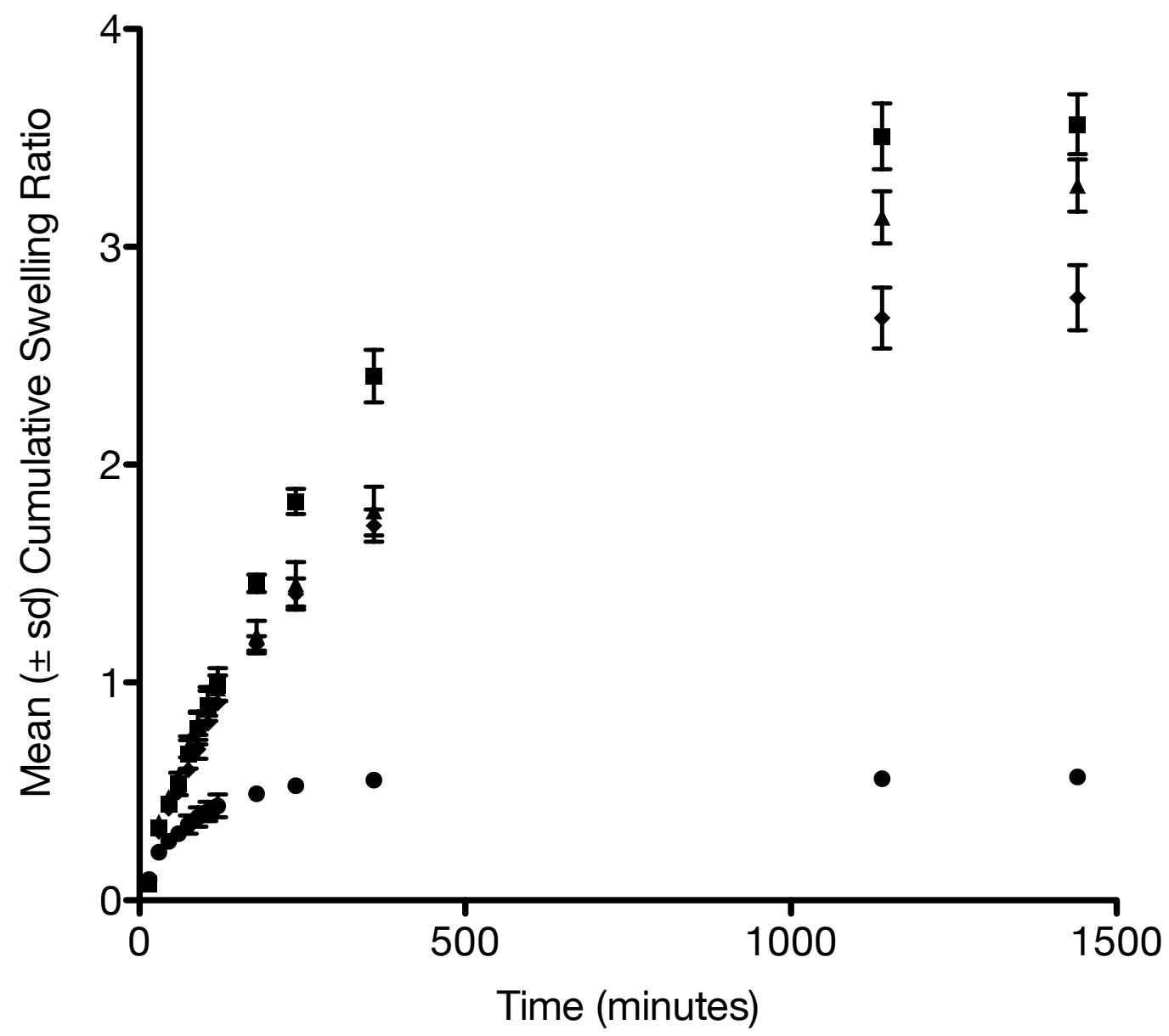


Figure 2

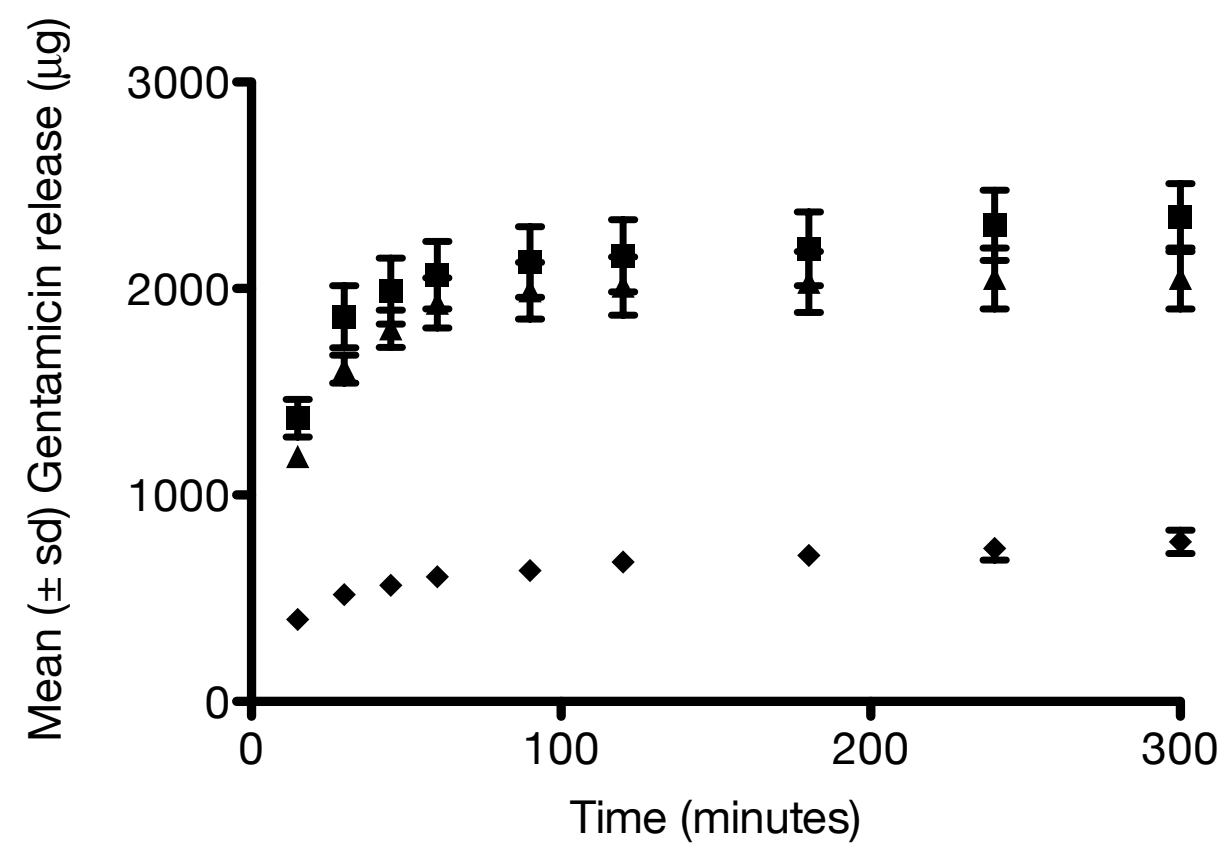

(a)

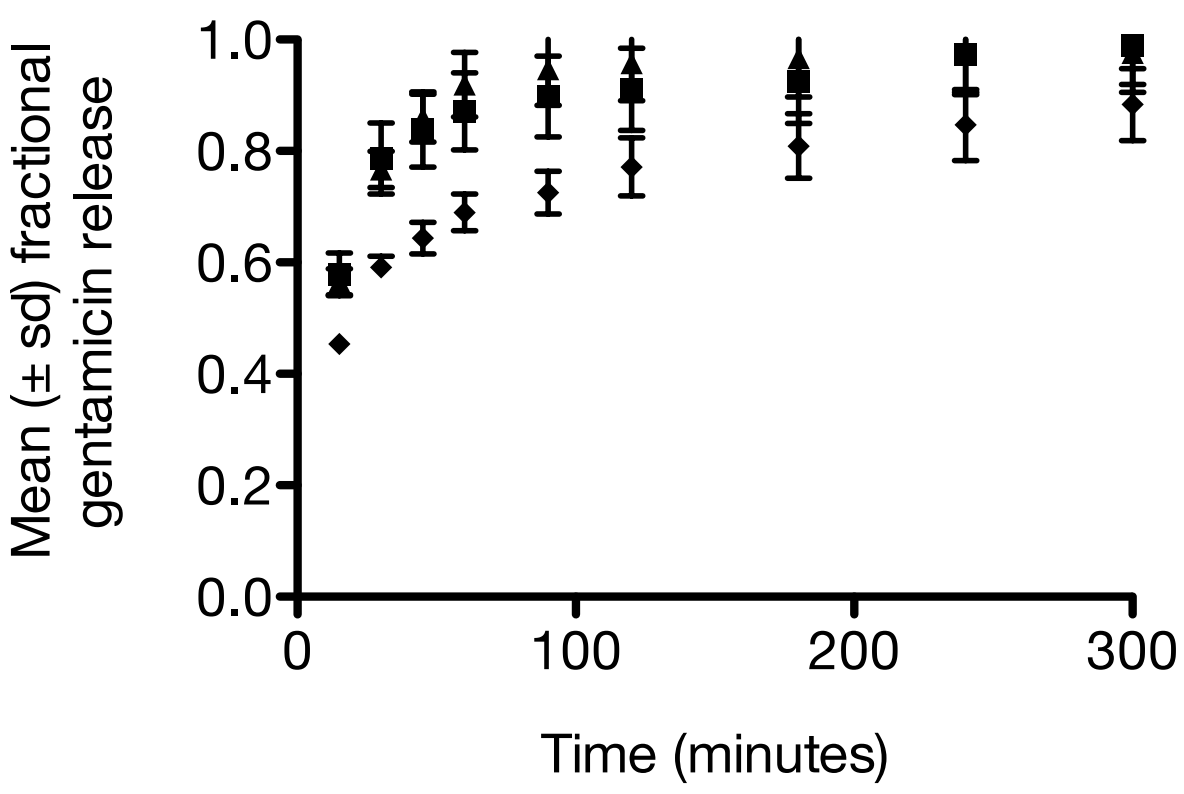

(b) 
Figure 3

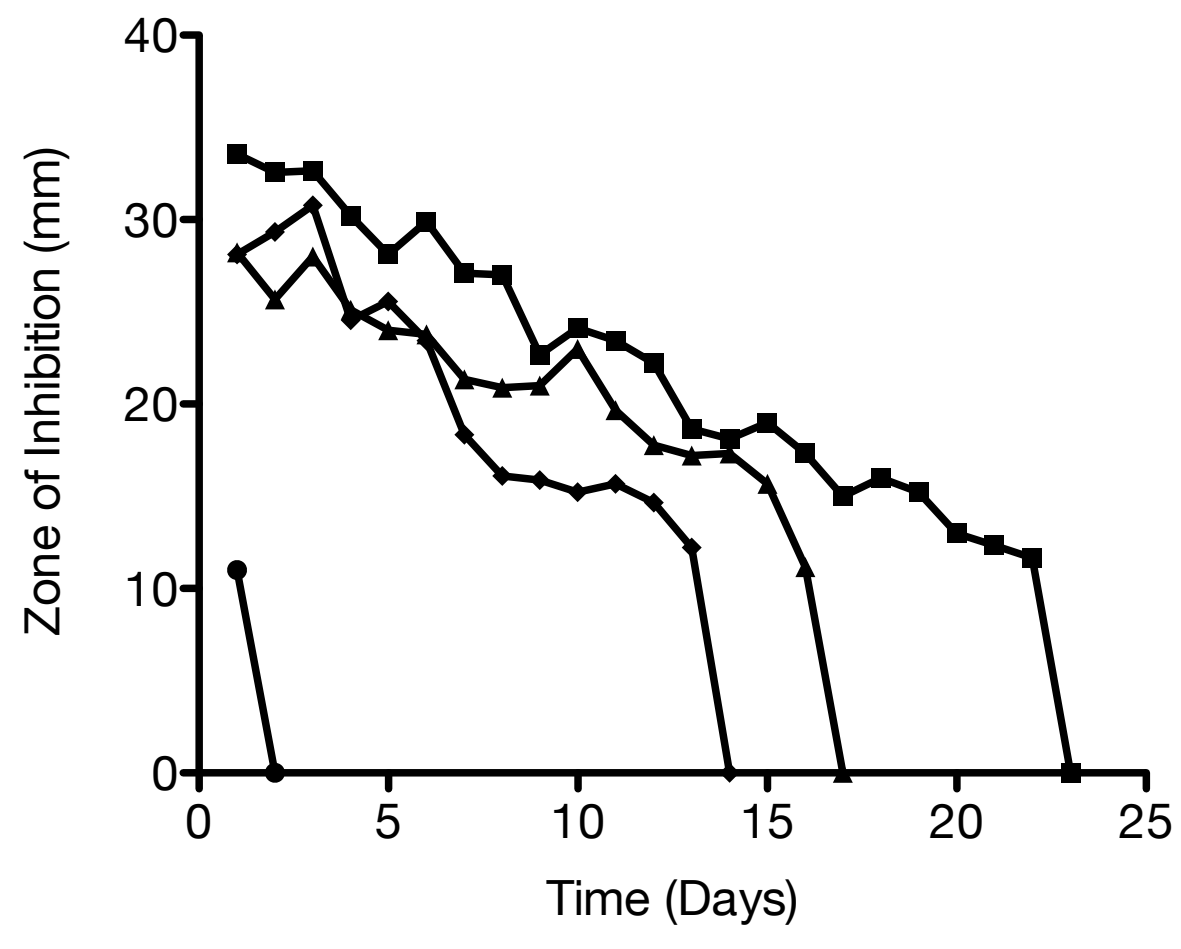


Figure 4

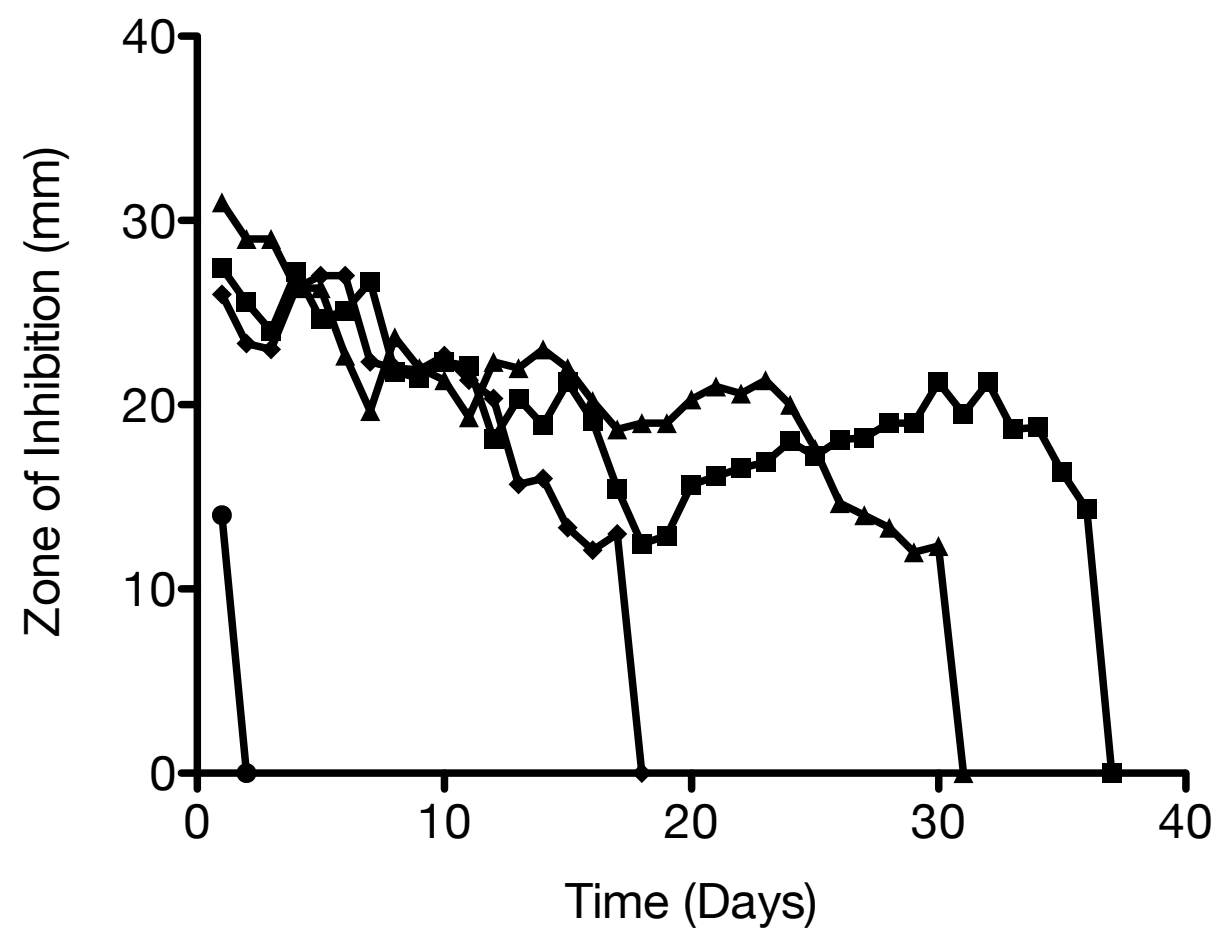

